ISSN: 0213-2087 e-ISSN: 2444-7080

DOI: https://doi.org/10.14201/shhcont372019159190

\title{
BÉLGICA ANTE LA REMILITARIZACIÓN DE LA RENANIA, 1936-1937
}

\author{
Belgium facing the remilitarization \\ of the Rhineland, 1936-1937
}

\author{
Jorge VARGAS VISÚS \\ Athénée Royal de Hannut (Bélgica)
}

Recibido: 13/05/2018 Revisado: 07/09/2019 Aceptado: 09/09/2019

RESUMEN: La remilitarización de Renania el 7 de marzo de 1936 se ha considerado una oportunidad perdida para poner a prueba la política internacional de Hitler. Se suele poner el foco del análisis en las reacciones británica y francesa. Sin embargo, el movimiento alemán implicó a otra potencia democrática: Bélgica. Hitler, con la remilitarización de Renania violó y denunció el Tratado de Locarno. Se abrió, como consecuencia de ello, un proceso de negociación destinado a establecer un nuevo pacto de seguridad occidental. Bélgica vio la oportunidad de redefinir su política exterior. Su empeño en lograrlo contribuyó a finiquitar lo que quedaba del sistema de seguridad colectiva establecido a través del Tratado de Locarno de 1925. colectiva.

Palabras clave: Remilitarización; Renania; Bélgica; Tratado de Locarno; Seguridad

ABSTRACT: The remilitarization of the Rhineland on March 7, 1936, has been considered as a missed opportunity to test Hitler's international policy. Historiography has focused on the analysis in the French and the British reactions to Hitler's action. However, the German movement involved another democratic power: Belgium. Through the remilitarization of the Rhineland the Locarno Treaty was denounced and violated by Hitler. Consequently, a new negotiation process was triggered in order to establish a new Western Security Pact. Belgium saw and seized the opportunity to redefine its foreign policy. This meant the end of the collective security system established by the Locarno Treaty in 1925 .

Key words: Remilitarization; Rhineland; Belgium; Locarno Treaty; Collective security. 


\section{INTRODUCCIÓN}

C'est un peu tard pour ne pas céder [...] C'est en 1936, dis-je, qu'il fallait ne pas céder. L’armateur haussa les épaules, eut un rire indigné. Ou méprisant.

Bien sûr! Vous auriez voulu qu'on se batte pour les rouges, en Espagne!» [...] «Je ne fais pas allusion à la guerre d'Espagne, monsieur ! Je parle de mars 36, pas de juillet $36 .$. C'est sur la Rhénanie qu'il fallait s'opposer à Hitler... Tout était encore possible !»1

Más allá de si entonces "todo" era posible todavía tras la remilitarización de la Renania por parte de Hitler el 7 de marzo de 1936, estas palabras de Jorge Semprún ponen el acento en uno de los acontecimientos clave de la historia del siglo XX. La remilitarización de la Renania conllevó la violación y la denuncia, por parte de Alemania, del Tratado de Locarno ${ }^{2}$. Dicha violación tuvo como consecuencia la apertura de un proceso de negociación, entre las llamadas potencias locarnianas, al objeto de establecer un nuevo pacto de seguridad occidental. El proceso nunca se culminó. De hecho, fue diluyéndose hasta que, en 1938, el «Anschluss» y la Conferencia de Múnich pusieron de manifiesto que las relaciones internacionales en Europa se regían a partir de un patrón que nada tenía que ver con el objetivo frustrado de un ya imposible nuevo Locarno.

Sobre la remilitarización de la Renania y su significado mucho se ha escrito. Ian Kershaw concluyó que «el triunfo de 1936, que tanto había fortalecido la seguridad en sí mismo de Hitler, resultó en este sentido no un final sino un principio» ${ }^{3}$. Sin embargo, pocos historiadores se han sumergido en el proceso negociador que se abrió fruto de la violación alemana del Tratado de Locarno.

Cuando en la historiografía se aborda Locarno se suele hacer al objeto de analizar las debilidades con las que nació. Ya antes de la remilitarización de Renania este tratado era objeto de análisis en los que se enfatizaban sus defectos. Es el caso de un artículo de Edward Grigg ${ }^{4}$. El autor consideraba a Locarno, ya en 1935, prisionero de

1. Semprún, Jorge, Adieu, vive clarté..., Paris: Gallimard, 1998, pp. 252-253.

2. Negociado en Suiza en octubre de 1925 y firmado en Londres el 1 de diciembre de ese mismo año, suponía la confirmación voluntaria por parte de Alemania de las fronteras occidentales con Francia y Bélgica, actuando británicos e italianos como garantes de tal compromiso. También implicaba la obligación de recurrir al arbitraje en caso de conflicto. El pacto hacía a la Sociedad de Naciones (SdN) competente para determinar el ejercicio de las garantías del acuerdo por los países firmantes. El tratado de arbitraje fue firmado por Francia, Bélgica, Polonia y Checoslovaquia con Alemania. Implicaba que, en caso de la violación del tratado, el litigio subsiguiente se habría de llevar ante el sistema de arbitraje dispuesto por la SdN, tal y como ocurrió tras la remilitarización de la Renania el 7 de marzo de 1936.

3. Kershaw, Ian, Hitler (1936-1945), Barcelona: Península, 2007, pág. 22.

4. Grigg, Edward, "The Merits and defects of the Locarno Treaty as a guarantee of world peace", International Affairs, Vol. 14, No2, Mar-Apr 1935, pp. 176-197. http://www.jstor.org/stable/2602086, fecha de consulta (10/06/2017), pág. 177. El autor destacaba la no implicación de los Estados Unidos en el Covenant, así como la primacía de la política imperial en la política exterior del Reino Unido. Una circunstancia, esta 
su contexto internacional. Posteriormente, y siguiendo la línea planteada por el artículo de Grigg, se incidió en la idea de que Locarno despertó ilusiones de paz basadas en una confianza ciega en los pactos que supuso, en sí misma, una herramienta muy útil para Hitler al objeto de respaldar diplomáticamente su política de agresión 5 . Una visión historiográfica que se completa con la proyección de Locarno, y del sistema de seguridad colectiva que estableció, para defender tesis relativas al fracaso de la actual política europea de defensa ${ }^{6}$.

Por su parte, Zara Steiner sí ha llevado a cabo un análisis de las consecuencias de la remilitarización de la Renania en su libro The Triumph of the Dark ${ }^{7}$ en el que sí se detiene en el proceso de negociación posterior a la violación de Locarno. Aparte de este análisis, apenas hay reflexiones acerca de ese proceso negociador que se entabló como un intento de establecer un nuevo pacto de seguridad occidental que garantizase la consolidación de la paz en la Europa de los años treinta del siglo XX $\mathrm{X}^{8}$.

El análisis que Steiner hace de la remilitarización de Renania parte de la consideración de que Hitler se decidió a dar el paso porque percibió que la situación internacional le favorecía. Mussolini atraía la atención del mundo con su guerra en Etiopía y se habían constatado fisuras en la entente anglo-francesa ${ }^{9}$. El acontecimiento abrió una nueva etapa del período de Entreguerras, determinada por la necesidad de Francia de

última, que abría una brecha con Francia en lo concerniente a la política a desarrollar en la Europa continental respecto a Alemania.

5. Duroselle, J. B. "The Spirit of Locarno: Illusions of Pactomania». Foreign Affairs, Vol. 50 N4, Jul, 1972, pp. 752-764. https://www.foreignaffairs.com/articles/russian-federation/1972-07-01/spirit-locarnoillusions-pactomania, fecha de consulta (6/04/2018), pág. 758.

6. Lindery-French, Julian, "In the shade of Locarno? Why European Defence is Failing", International Affairs, Vol. 78, No4, Oct. 2002, pp. 789-811.

7. STEINER, Zara, The Triumph of the Dark: European international history 1933-1939, Oxford: Oxford University Press, 2011.

8. Cuando se han analizado las consecuencias de la remilitarización de la Renania se ha hecho poniendo el foco en las reacciones inmediatas, sobre todo de Francia, ante este movimiento alemán. Es el caso de Parker, R., "The first capitulation: France and the Rhineland crisis of 1936", World Politics, Vol. 8, No3 (Apr. 1956), pp. 355-373. http://www.jstor.org/stable/2008855; así como de CAIRNs, John, "March 7, 1936 again: The view from Paris", International Journal, 230 (1965), pp. 230-246; de ScHukER, Stephen A., "France and the remilitarization of the Rhineland", French Historical studies, Vol. 14, No3 (Spring 1986), pp. 299-338, http://www.jstor.org/stable/286380, y de AleXander, Martin S., "French military intelligence responds to the German remilitarization of the Rhineland, 1936 - The military consequences for France of the end of Locarno", Intelligence and National Security, 22:4, pp. 563-572, http://dx.doi.org/10.1080/02684520701640548. Otra perspectiva interesante de este asunto es la que viene dada por el estado de las relaciones diplomáticas franco-británicas y su posible influencia sobre la reacción a la crisis renana: DAVIS, Richard, "Le débat sur "l'appeasement" britanique et français dans les années 30. Les crises d'Ethiopie et de Rhénanie», Revue d'bistoire moderne et contemporaine, tome 45, No4, Octobre-Décembre 1998, pp. 822-836, https://www. persee.fr/doc/rhmc_0048-8003_1998_num_45_4_1939.

9. STEINER, Zara, «The Triumph...», op. cit., p. 137. 
lograr el apoyo de Bélgica y de Reino Unido para tomar la iniciativa y actuar frente a la provocación alemana. Tal y como afirma Steiner, durante 1936 no logró el apoyo de ninguno de los dos estados mencionados. En 1937 y 1938 Francia se avino con el Reino Unido. No sucedió lo mismo con Bélgica. Los belgas se retiraron de la primera línea diplomática contribuyendo de manera destacada al fracaso de las negociaciones que se entablaron al objeto de recuperar el sistema de seguridad colectiva que representaba el tratado de Locarno.

Por lo tanto, la remilitarización de Renania deshilachó todo un sistema de equilibrio internacional basado en la solidaridad interaliada. El objeto de este artículo es explicar cómo ese sistema de seguridad colectiva se disolvió como un azucarillo en el café sin que Hitler tuviese que presionar para ello. Solamente se limitó a contemporizar y a bloquear las negociaciones mientras se limitaba a recoger los frutos de la incapacidad de las potencias aliadas para establecer una base mínima común de negociación. En este sentido se incidirá en el rol jugado por la diplomacia belga. Su movimiento de retirada de la primera línea diplomática europea en busca de la recuperación de un status de neutralidad fue determinante para hacer descarrilar las negociaciones antes de que Hitler o Mussolini tuviesen que molestarse en hacerlo ellos mismos.

Para todo ello se ha consultado documentación de archivo $^{10}$ a partir de la que poder reconstruir cómo se produjo esa retirada de la primera línea diplomática europea por parte de Bélgica y cuáles fueron las razones que llevaron a este país a redefinir una nueva política internacional que bautizaron como la política de independencia.

\section{RENANIA}

El trauma que la I Guerra Mundial generó en Bélgica impuso en el país un estado de alerta que, a pesar de las exigentes disposiciones que el Tratado de Versalles imponía a la derrotada Alemania, se mantuvo en un nivel de intensidad que traspasaba sobradamente los umbrales de la desconfianza hacia su sometido vecino.

Así, a pesar de la firma del Tratado de Locarno en 1925, su diplomacia no rebajó la vigilancia sobre lo que pudiese acontecer al otro lado del Rin. Y la desconfianza era tal que, en 1928, las autoridades belgas ya veían a Alemania como una amenaza. Un país con ganas de revancha y con la firme intención de iniciar su rearme ${ }^{11}$.

Los acontecimientos que se sucedieron en los años posteriores no dieron tampoco respiro a esta preocupación belga. La ocupación militar de Renania por parte de las

10. Entre la documentación consultada destacan los fondos Locarno y Renania de los Archivos Diplomáticos Belgas en Bruselas, así como los Cabinet Papers de los National Archives en Londres.

11. "Note au Ministre», Bruselas, 14/01/1928, Fonds Rbénanie 11.309, Archives Diplomatiques Belges (ADB). 
tropas de las potencias aliadas era una de las salvaguardas incluidas en el Tratado de Versalles. En el texto del mismo se especificaban tres zonas de ocupación que se evacuarían a los 5, 10 y 15 años tras la ratificación del tratado. Dicha ratificación tuvo lugar en 1920 por lo que en 1930 debería haberse llevado a cabo la segunda de las evacuaciones. Sin embargo, como gesto de buena voluntad hacia la República de Weimar y su política de reconciliación, se decidió la retirada completa en ese año de 1930. Los belgas se sintieron desprotegidos. A esta circunstancia se sumó el hecho de que Adolf Hitler fuese nombrado Canciller en enero de 1933. Al otro lado del Rin había triunfado el discurso revisionista. Motivos suficientes para que las autoridades belgas comenzaran a inquietarse seriamente ${ }^{12}$.

La nueva situación internacional de Bélgica no se vio condicionada solamente por la política del nuevo gobierno alemán. También el bloque de los aliados despertó recelos entre los funcionarios del Ministerio de Exteriores. Desde el final de la I Guerra Mundial la diplomacia belga constataba que existían en Europa dos políticas en pugna respecto a Alemania. Francia estaba decidida a asegurar mediante una paz inmisericorde la seguridad de las generaciones futuras. Por otro lado, Reino Unido, una vez la flota de guerra alemana había desaparecido, no percibía peligro desde Alemania y volvía a dejarse llevar por una visión diplomática secular que determinaba que la clave de su política europea era evitar las hegemonías continentales ${ }^{13}$.

El resultado del desarrollo paralelo de ambas políticas, según la interpretación que se realizó en Bruselas, fue que Reino Unido puso límites a la política francesa respecto a Alemania. Una línea de acción que, según el director general de la política del Ministerio de Asuntos Exteriores, Pierre Van Zuylen, llevó a Londres, comprendiendo también el deseo de seguridad de Francia, a concebir la idea de un pacto de mutua garantía en el que Alemania participara en pie de igualdad con el resto de potencias firmantes. Se trató del origen de Locarno ${ }^{14}$. Según Van Zuylen la idea original que llevó a dicho tratado se fraguó en Londres. Habrían sido los británicos los que instaron a los alemanes a realizar la propuesta que posteriormente cristalizó en lo que, en Bruselas y en 1933, era considerado como la garantía de la integridad del territorio belga. Suponía la confirmación voluntaria por parte de Alemania de las fronteras occidentales con Francia y Bélgica, así como la obligación de recurrir al arbitraje.

Firmado Locarno y evacuada Renania en 1930, Bélgica tenía muy claras en 1933 cuáles debían ser las líneas de actuación a seguir en política exterior. En primer lugar, aclarada su interpretación restrictiva del acuerdo militar franco-belga de $1920^{15}$, impuso

12. De Brocheville, Charles, «Note au Ministre P. Hymans», 8/03/1933, Fonds Rhénanie 11.309, ADB.

13. VAn ZuYlen, "Locarno et la politique belge», 22/02/1933, Fonds Locarno 11.115, ADB, p. 3.

14. Ibid., p. 6.

15. Tras la I Guerra Mundial la diplomacia belga se embarcó en un proyecto de relaciones exteriores que persiguió garantizar su seguridad a través de su compromiso con las disposiciones del Tratado 
la prudencia en sus relaciones con Francia para evitar verse arrastrada a un posible conflicto provocado por la política de mano dura que los franceses deseaban mantener con Alemania. En segundo lugar, entendió que debía posicionarse en la línea política británica, pues no tenía nada que ganar si estallaba un conflicto. En ese sentido se deseaba evitar dar la impresión de que se quisiera defender el interés francés. Se transmitió que los únicos compromisos de Bélgica con Francia eran los que establecía el Tratado de Locarno. Finalmente, se deseaba trabajar por normalizar las relaciones con Alemania ${ }^{16}$.

Así, el 2 de octubre de 1935, en sesión de la comisión de asuntos exteriores del Senado, el primer ministro y ministro de exteriores, Paul Van Zeeland, declaró que el gobierno belga continuaba siendo fiel a la política que se derivaba de su estatus internacional — determinado por Versalles y Locarno—, aunque consideraba la política exterior del país como una política independiente que respetaba sus compromisos internacionales pero que no estaba obligada a ir más allá de las responsabilidades comunes ${ }^{17}$. Y así, con una reinterpretación del alcance de su acción exterior respecto a sus compromisos firmados hecha pública en sede parlamentaria, Bélgica fue testigo de cómo el 7 de marzo de 1936 Alemania procedió a remilitarizar Renania, denunciando de manera unilateral el Tratado de Locarno.

Mientras los destacamentos de infantería alemana penetraban en Renania y ocupaban las instalaciones militares, Hitler pronunciaba en el Reichstag un discurso en el que reclamaba la igualdad de derechos entre los estados para una plena colaboración europea $^{18}$. Para la búsqueda de esa colaboración con Francia y el resto de potencias signatarias de Locarno, argumentaba Hitler en su discurso, su gobierno había enviado ese mismo día un memorándum a los embajadores de Reino Unido, Italia, Francia y al encargado de negocios belga en el que se recogía la razón de su movimiento repentino, además de una serie de propuestas que pretendían ser la base para una negociación de cara a edificar un nuevo sistema de mantenimiento de la paz en Europa ${ }^{19}$.

El memorándum denunció que las obligaciones asumidas por Francia a través del pacto firmado con la Unión Soviética el 2 de mayo de 1935 no eran compatibles con las asumidas en el Tratado de Locarno. Afirmó el gobierno alemán que era incontestable que este pacto se había constituido contra Alemania y que llevaba a Francia a asumir

\footnotetext{
de Versalles, así como con la firma de tratados defensivos bilaterales. En este sentido se firmaron el pacto franco-belga de 1920 y el acuerdo defensivo con Reino Unido de 1922. En 1925 firmó el Tratado de Locarno.

16. VAn ZuYLEN, «Locarno et la politique belge», Bruselas, 22/02/1933, Fonds Locarno 11.115, ADB, pp. 17-29.

17. VAN ZeELAND "Circulaire aux agents diplomatiques belges à l'étrangère», Bruselas, 19/10/1935, Fonds Locarno 11.115, ADB.

18. "Les propositions de Hitler", La Dernière Heure, 8/03/1936, p. 3.

19. Ministère AA.EE Belgique, «Discours prononcé au Reichstag le 7 Mars 1936 par le Führer et Chancelier du Reich, Aldolf Hitler», Fonds Rhénanie 11309, ADB, p. 38.
} 
obligaciones que iban más allá del alcance de los Tratados de Versalles y de Locarno. Por esta razón, concluyó el documento, el pacto de Locarno había perdido su significación y había dejado de existir. En consecuencia, Alemania no se consideraba ligada a un tratado caduco $^{20}$. De esta manera, el gobierno alemán había violado Locarno al ocupar la zona desmilitarizada, y lo había denunciado en tan solo unas horas a través del discurso de Hitler y del memorándum enviado a las potencias signatarias del pacto.

El documento, así como el discurso de Hitler, se completaron con una serie de propuestas a través de las que el canciller emplazó a los estados signatarios de Locarno a una negociación que diese forma a un nuevo sistema que garantizase la paz en Europa. Las propuestas se basaron en dos premisas. La primera, la proclamación de un nuevo estatus internacional para Alemania basado en la igualdad de derechos para con el resto de potencias europeas. La segunda, el restablecimiento de la plena y entera soberanía del Reich en la zona desmilitarizada de Renania ${ }^{21}$.

Desde esa nueva posición, el Reich propuso negociar con Bélgica y con Francia la creación de zonas desmilitarizadas a ambos lados de las fronteras y la firma de un tratado de no agresión por un período de 25 años. Invitó a Reino Unido y a Italia a actuar como garantes de ese pacto y abrió la puerta también a la inclusión, igualmente como garante, de los Países Bajos. Finalizó anunciando que, desde el momento en el que la paridad de derechos hubiera sido restablecida y que la soberanía del gobierno alemán fuera plena sobre todo su territorio, el gobierno del Reich se mostraría dispuesto a volver a ser miembro de la Sociedad de Naciones ( $\mathrm{SdN}$ ).

Los primeros movimientos del ejecutivo belga tras los sucesos del 7 de marzo fueron de tanteo, a la espera de las reacciones que se produjesen tanto en Reino Unido como en Francia. Los primeros telegramas que se recibieron desde Londres no dejaron lugar a la duda respecto a que el gobierno británico impuso la prudencia como principio director de la reacción a la crisis desatada por $\mathrm{Hitler}^{22}$, al objeto de intentar capitalizar las ofertas alemanas ${ }^{23}$.

Por su parte, Francia consideró que esta denuncia unilateral de Locarno debía tener como consecuencia la aplicación del procedimiento de infracción previsto por el tratado, por ello comunicó a las potencias signatarias que deseaba que la cuestión fuese sometida al Consejo de la SdN lo antes posible. El gobierno francés deseaba que esta autoridad emitiese una condena formal contra Alemania, aplicase sanciones económicas y financieras, activase las cláusulas de asistencia mutua y nombrase una comisión de control sobre las actividades de las tropas alemanas en Renania. Se mostró también dispuesta a someter a examen el pacto franco-soviético que servía al gobierno

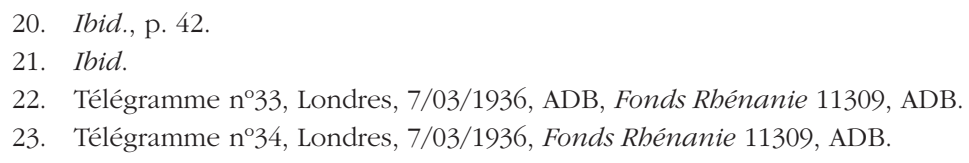


del Reich para justificar su acción. Y, finalmente, anunció que no se mostraba contraria a negociar con Hitler a condición de que éste retirara la denuncia de Locarno, abandonase la idea de crear las zonas desmilitarizadas entre las fronteras de Bélgica, Francia y Alemania, y de que retirase las tropas de la zona desmilitarizada ${ }^{24}$.

El Consejo de Ministros belga se reunió el día 8 de marzo al objeto de evaluar los acontecimientos de la víspera ${ }^{25}$. Van Zeeland informó de que el encargado de negocios belga en Berlín había comunicado al gobierno alemán que se había constatado una violación flagrante de un compromiso libremente adquirido por Alemania, y que el pretexto formulado por esta, el pacto franco-soviético, no podía desligar a Alemania vis-à-vis de Bélgica. Por ello, el Consejo aprobó la presencia de Van Zeeland en Ginebra, así como el envío al Consejo de la SdN de una comunicación ${ }^{26}$ por la que Bélgica denunciaba que la acción de Alemania contravenía los artículos $42-43$ del Tratado de Versalles y que, por lo tanto, el gobierno belga, conforme al artículo 4, párrafo 1 del Tratado de Locarno, llevaba inmediatamente la cuestión al Consejo de la SdN pidiendo su convocatoria lo antes posible. La misma tarde del día 8 se comunicó a los gobiernos de Francia, Reino Unido e Italia el contenido de ese texto enviado a la SdN, y se les instó a hacer lo mismo.

Por su parte, la reunión del gabinete británico para tratar lo sucedido en Renania tuvo lugar el 9 de marzo de 1936 a las once de la mañana. Los ministros británicos abordaron la cuestión contando con el apoyo de un documento ${ }^{27}$ en el que se analizaba el memorándum alemán y se recogían una serie de reflexiones sobre la nueva situación europea. No se aceptó la justificación esgrimida por Hitler para tomar la decisión de remilitarizar Renania y denunciar Locarno, puesto que ningún argumento podría justificar la denuncia unilateral del tratado. Alemania había decidido sola una cuestión que debía haber sido sometida a arbitraje. Sin embargo, el texto llama la atención sobre el hecho de que:

as regards the reoccupation of the Rhineland, it is relevant to recall here that the possibility of negotiations between the Locarno Powers, which might have culminated in authorising its re-occupation by Germany, was already under consideration in London ${ }^{28}$.

El ministro citaba en ese mismo documento otro memorándum, fechado el 14 de febrero, en el que ya se planteaba la posibilidad de negociar con Alemania para evitar

24. Télégramme n45, París, 7/03/1936, 11309, ADB.

25. "Seance du Conseil de Ministres 8/03/1936 No72", Procès verbaux du Conseil de Ministres BE-A0510 / I 252/04, Archives Généraux du Royaume (AGR).

26. "Appel au Conseil de la SdN", 8/03/1936, Fonds Rhénanie 11309, ADB.

27. EDEn, Anthony, "Germany and the Locarno Treaty", 8/03/1936, The cabinet papers, The National Archives (TNA). http://filestore.nationalarchives.gov.uk/pdfs/small/cab-24-261-CP-73-2.pdf, fecha de consulta 2/11/2016.

28. Ibid., p. 1 
una confrontación o una situación similar a la que en ese momento se presentaba. Ambos documentos dieron consistencia a las tesis belgas sobre las diferencias entre las intenciones francesas y británicas respecto a Alemania, expresadas en el informe de febrero de 1933 del barón Van Zuylen, ya citado en este texto. En la página cuatro del memorándum se informó de que Bélgica había trasladado la cuestión al Consejo de la SdN y que, al mismo tiempo, había pedido que todos los signatarios de Locarno hiciesen lo mismo. Reino Unido, tal y como informó Eden, rechazó esa petición. Su política respecto a este asunto pasaba por negociar con Hitler. Para ello era condición previa evitar cualquier acción militar de Francia contra Alemania. Al objeto de dar también cierta satisfacción a Francia, aseguró el cumplimiento de sus responsabilidades como garante en el caso de que esta fuese agredida por Alemania ${ }^{29}$.

Una vez constatadas las reacciones de Francia y, sobre todo, de Reino Unido, la diplomacia belga corroboró cómo la actitud firme de Francia chocó con la actitud de un gobierno británico que en ese momento y a raíz de lo sucedido vio una oportunidad de negociar con Alemania. Esta constatación, unida a un miedo real respecto a una posible invasión ${ }^{30}$ y a la perspectiva ofrecida por la reunión de los titulares de exteriores de Francia, Inglaterra, la propia Bélgica e Italia —-finalmente al encuentro acudió su embajador - prevista para el día 10 de marzo en París, llevó a la diplomacia belga a definir una actitud basada en actuar a remolque de lo que otras potencias decidiesen ${ }^{31}$.

De manera que, con la intención cada vez más firme de restringir la asunción de responsabilidades a lo mínimamente exigible para cumplir con su compromiso y de verificar las posiciones de Reino Unido y Francia, Van Zeeland acudió a París para la reunión del 10 de marzo con sus homólogos francés, Pierre-Étienne Flandin, e inglés, Anthony Eden —además del embajador de Italia-. El encuentro puso de manifiesto las posturas encontradas de británicos y franceses. Los últimos se negaron a cualquier negociación con Hitler hasta que la ley internacional no hubiese sido restablecida ${ }^{32}$. Ante las divergencias, Van Zeeland se mostró prudente y aplicó la línea de acción recomendada por sus funcionarios. Cuando el embajador británico en Francia le preguntó si debían asumir que la posición belga era la misma que la de los franceses, respondió que pensaba que la solidaridad entre Reino Unido y Francia era indispensable para la resolución de la crisis, por ello afirmó que apoyaría los acuerdos que se alcanzaran y que mediaría en el caso de que se constatasen diferencias ${ }^{33}$. Posteriormente aclaró su posición a Eden, explicando que las negociaciones con Alemania no podían aparecer

\footnotetext{
29. Ibid., pp 4-6.

30. RaQUEZ, "Rapport N² R. P/1138", 9/03/1936, Fonds Locarno 11.115, ADB.

31. "Attitude de la Belgique", 9/03/1936, Fonds Locarno 11.115, ADB.

32. "Compte rendu résumé réunion au Quai d'Orsay", 10/03/1936, Fonds Locarno 11.115, ADB.

33. "Memorándum de la conversation entre M. Van Zeeland et Sir George Clark", 10/03/1936, Fonds
} Locarno 11.115, ADB. 
como una prima a la violación del Tratado. Para Bélgica la desmilitarización tenía una importancia considerable y, por lo tanto, lo que quedaba era que la solución, a la par que conciliadora, fuese firme y, sobre todo, pasase por un acuerdo entre Francia y Reino Unido. El ministro británico manifestó a Van Zeeland su sorpresa por la firmeza de la posición francesa y aseguró que eso le obligaba a retrasar su respuesta a la petición belga hasta que no se tratase la cuestión de nuevo en el gabinete ${ }^{34}$. Dadas las circunstancias, Eden emplazó a los asistentes a una nueva reunión en Londres que se celebraría el 12 de marzo ${ }^{35}$.

Para dar cuenta de las conversaciones de París y preparar las entrevistas de Londres, el gabinete británico se reunió el miércoles 11 de marzo. Eden afirmó ante sus colegas que en principio la política británica de negociación con Alemania para restablecer el equilibrio europeo no tenía oportunidad de ser aceptada, dadas las posiciones francesa y belga — mucho más ambigua esta última a la espera de la evolución de los acontecimientos— ${ }^{36}$. A pesar de este contratiempo, el gobierno británico se reafirmó en su posición y rechazó la idea francesa de forzar a los alemanes a abandonar Renania. De cara a las conversaciones del día siguiente, el gabinete estableció tres presupuestos sobre los que basar una posible negociación para dar forma a un nuevo contexto internacional: En primer lugar, la restitución de la moralidad internacional — pisoteada por Alemania al denunciar Locarno de manera unilateral-; en segundo lugar, ofrecer a Alemania una posición razonable en el tablero europeo; y en tercer lugar, dar a Francia y a Bélgica la garantía de apoyo en cualquier nuevo tratado que sustituyese a Locarno.

En estas circunstancias, Van Zeeland compareció ante el Parlamento el día 11 de marzo, antes de viajar a Londres para asistir a la conferencia prevista para el día 12, al objeto de informar sobre las conversaciones del día 10 en París. Su discurso ${ }^{37}$ constató dos cosas importantes. La primera fue el estado de preocupación y miedo del gobierno ante las incertidumbres de la situación europea y la gravedad de lo sucedido respecto al conjunto de elementos que conformaban la seguridad belga. La segunda fue la confirmación del primer paso hacia una nueva política exterior a raíz del anuncio del final de la vigencia, con matices, del Acuerdo Militar franco-belga de 1920. El primer ministro belga anunció que se había acordado con Francia mantener el único punto del acuerdo que tenía vigencia: el contacto entre estados mayores para ejecutar compromisos de Locarno.

34. "Conversation entre MM Eden et Van Zeeland", 10/03/1936, Fonds Locarno 11.115, ADB.

35. "Conversation entre M. Eden et M. Van Zeeland à 17h", 10/03/1936, Fonds Locarno 11.115, ADB.

36. "Cabinet 18 (36)», 11/03/1936, The cabinet papers, TNA, pág. 286. http://filestore.nationalarchives. gov.uk/pdfs/small/cab-23-83-cc-18-36-18.pdf, fecha de consulta 02/11/2016.

37. Bulletin Périodique de la Presse Belge No122, París, 23/05/1936, Bibliothèque Nationale de France (BNF), pp. 4-7. http://gallica.bnf.fr/ark:/12148/cb32732708n/date, fecha de consulta 16/6/2015. 
A lo largo del discurso, el primer ministro belga también desarrolló un argumento interesante que reflejaba la posición que Bélgica iba a adoptar durante las negociaciones que debían desarrollarse en los días posteriores. Asegurando que la preocupación dominante de los estadistas debía ser la de hacer todo lo posible para reducir y eliminar el riesgo de guerra, no solo en el presente sino también de cara al futuro, se comprometió a mantenerse fiel al articulado de Locarno en tanto no hubiera otro texto que lo sustituyera, mostrando de esta manera su disposición a negociar ${ }^{38}$.

Durante las entrevistas del día 12 de marzo en Londres se constató que Francia no cedía en su demanda de la retirada alemana, que Bélgica adoptó una posición más moderada, en línea con el discurso de Van Zeeland del día anterior, y que Reino Unido seguía empeñado en utilizar las demandas de Hitler para obtener un acuerdo permanente ${ }^{39}$. Así pues, esta última potencia entregó una serie de propuestas a los representantes de Francia, Bélgica e Italia a través de las que pretendía fijar un punto de partida desde el cual afrontar un proceso negociador con Alemania ${ }^{40}$. Teniendo en cuenta la propuesta de resolución presentada por Francia en el Consejo de la SdN, y reconociendo que la acción unilateral alemana entrañaba un conflicto con los principios del Derecho Internacional ${ }^{41}$, se establecía que como consecuencia de sus actos el gobierno alemán carecía de derechos legales y que esta acción unilateral introducía un elemento perturbador en la situación internacional que amenazaba la seguridad europea ${ }^{42}$.

A partir de este punto de partida, la diplomacia británica llevaba la situación a su terreno al proponer la vía de la negociación con Alemania. Invitó al gobierno alemán a llevar a la corte de arbitraje su argumento relativo a la incompatibilidad del acuerdo franco-soviético con el Tratado de Locarno y a comprometerse con algunas medidas provisionales $^{43}$ mientras no se lograse la conclusión de un nuevo tratado. Con la vista puesta en ese objetivo, se propuso que el proceso negociador debía basarse en los siguientes elementos —acordados por las cuatro potencias-: El examen de las propuestas 2 a 5 del memorándum alemán, la revisión del estatus de Renania y el establecimiento de pactos de asistencia mutua abiertos a todos los signatarios de Locarno con el objetivo de reforzar su seguridad ${ }^{44}$. Este texto de propuestas se concretó en los

38. Ibid., p. 7.

39. "Cabinet 20 (36)", 16/03/1936, The cabinet papers, TNA. http://filestore.nationalarchives.gov.uk/ pdfs/small/cab-23-83-20.pdf, fecha de consulta 2/11/2016.

40. "Text of proposals drawn up by the Representatives of Belgium, France, United Kingdom of Great Britain and Northern Ireland and Italy», 19/03/1936, 11.179 (2), ADB.

41. Ibid., p. 2.

42. Ibid.

43. No aumentar el número de las tropas destacadas ni de tropas paramilitares, así como no llevar a cabo trabajos de fortificación en el área renana. Ibid. pág. 3.

44. Ibid., p. 4. 
acuerdos de Londres de 19 de marzo de 1936. La esencia de lo acordado fue que las disposiciones de Locarno seguían vigentes hasta que se negociase un nuevo acuerdo que estableciese una nueva relación entre las potencias en Europa occidental ${ }^{45}$.

Por lo tanto, Reino Unido impuso su voluntad de negociar con Alemania. Se abrió así un proceso negociador que no tuvo punto y final, pues no se concretó ningún "Locarno II". En lo que a Bélgica respecta, estos acuerdos del 19 de marzo, que fueron aprobados por su Consejo de Ministros al día siguiente ${ }^{46}$, mantuvieron al país como parte integrante de un sistema de seguridad colectiva ya moribundo. Más adelante iban a suponer un obstáculo para el reconocimiento de los cambios en su política exterior, pero por de pronto abrieron un nuevo panorama en el que era necesario sentarse a negociar.

Así las cosas, el secretario general del Ministerio de Asuntos Exteriores, Fernand Van Langenhove, fijó dos objetivos esenciales para la política exterior de Bélgica. El primero fue evitar que el país se viese implicado en un conflicto. El segundo, en el caso de que el conflicto estallara, contar con la asistencia de Francia y de Reino Unido ${ }^{47}$. Convencido de que la base del principio de seguridad colectiva estaba profundamente dañada, y con la impresión de que las conversaciones no iban a llegar a buen puerto, Van Langenhove concluyó que los peligros que presentaba el escenario internacional hacían que lo más aconsejable para Bélgica fuera aprovechar la circunstancia del momento para desligarse de los lazos que la asociaban a la política de las grandes potencias y así volver a desarrollar su papel de estado-barrera ${ }^{48}$. De cara a materializar esta aspiración, Langenhove abogó por desarrollar una política de equilibrio y una actitud imparcial para evitar lazos exclusivos de hecho o de derecho con una u otra potencia ${ }^{49}$.

Este informe tiene una importancia capital, pues recoge la esencia de lo que en poco tiempo iba a denominarse la "política de independencia". La acción exterior belga iba a trabajar para desembarazarse de sus compromisos internacionales. A corto plazo eso significó una serie de directrices con las que acudir a las negociaciones del nuevo pacto occidental. Se asumió que era deseable que Bélgica no adquiriese ninguna obligación de asistencia fuera de lo previsto por el pacto de la SdN. En este sentido se preveían como aceptables tres posibles escenarios: El primero implicaría un nuevo pacto renano similar al de 1925, pero sin asumir ninguna obligación de asistencia respecto a los garantes y solamente adoptando el compromiso de defender sus propias fronteras

45. "Seance 20-Mars-1936», Annales Parlementaires, pág. 918. http://www3.dekamer.be/digidocanha/ K0042/K00421123/K00421123.PDF, fecha de consulta 28/01/2017.

46. "Séance du Conseil de Ministres du 20/03/1936, N75", Procès verbaux du Conseil de Ministres BE-A0510 / I 252/04, AGR.

47. Van Langenhove, "Note de M. Van Langenhove», 7/04/1936, Fonds Locarno 11.115, ADB, p. 1.

48. Ibid., pp. 7-8.

49. Ibid., p. 10 . 
en caso de ataque; el segundo admitía la conclusión con Alemania, y eventualmente con otros vecinos, de un pacto de no agresión que, en virtud de otro acuerdo superior en el que Bélgica no participaría, quedase emplazado bajo la garantía de las potencias occidentales firmantes; el tercero de los escenarios contemplaba la firma de un acuerdo colectivo de asistencia mutua que fuese concluido entre las potencias occidentales aunque sin la participación belga. Dicho acuerdo recogería que la violación de las fronteras belgas implicaría la aplicación a Bélgica de la asistencia prometida entre los firmantes al mismo nivel que si se tratase de una agresión dirigida contra su propio territorio ${ }^{50}$.

La diplomacia belga deseaba el tercero de los escenarios como aquel que debía cristalizar fruto de las negociaciones. El diagnóstico que el servicio exterior belga realizó de la situación europea y de las posiciones de sus aliados no era nada halagüeño, y fue por este motivo que se profundizó en la idea de defender el tercer escenario de cara a la conferencia de potencias locarnianas que había de celebrarse a finales del mes de julio en Bruselas. Los informes instaban al nuevo ministro de exteriores, Paul-Henri Spaak, a que abandonase la línea de conducta que había llevado a los acuerdos del 19 de marzo y que defendiese la idea de un Locarno limitado a las grandes potencias, pero que al mismo tiempo contuviese un compromiso de no agresión, y de asistencia en caso de agresión, en favor de Bélgica y Países Bajos ${ }^{51}$. El objetivo que se perseguía era garantizar la seguridad del país evitando que se viese arrastrado a un conflicto entre grandes potencias. Para ello se instó al gobierno a desarrollar una política enteramente independiente y desligada de todo lazo exclusivo ${ }^{52}$. El nuevo ministro de exteriores no iba a tardar en hacer público este cambio de orientación de la política exterior belga.

\section{LA NUEVA POlítica EXTERIOR DE BÉlgiCA}

Los acuerdos de Londres del 19 de marzo de 1936 establecieron un marco de relaciones internacionales meramente provisional. Sin embargo, y a pesar de esta provisionalidad, implicaron la reafirmación de Locarno por parte de las potencias signatarias del pacto original, excepto Alemania, y por consiguiente nada las absolvía de ninguna obligación o garantía hasta que se firmase una nueva convención ${ }^{53}$.

50. "Examen critique des principales formules à envisager en vue de la révision du pacte Rhenan", 30/04/1936, Fonds Locarno 11.115, ADB.

51. Van ZuYlen, «Note pour Monsieur le Ministre», 7/07/1936, Fonds Locarno 11.115, ADB, pp. 10-11.

52. Langenhove, F. «Note sur la polítique à suivre en vue de garantir notre sécurité», 7/07/1936, Fonds Locarno 11.115, ADB, pp.3-4.

53. Eden, Anthony "Germany and the Locarno Treaty C. P. 79 (36)", 15/03/1936, The cabinet papers, TNA, http://filestore.nationalarchives.gov.uk/pdfs/small/cab-24-261-CP-79-3.pdf, fecha de consulta 2/11/2016. Las previsiones de este documento se materializaron en los acuerdos del día 19 de marzo. 
Paul-Henri Spaak, nuevo ministro de exteriores de Bélgica a partir del 14 de junio de 1936, fue recibido por sus servicios diplomáticos con una rápida puesta al día sobre la situación internacional en Europa ${ }^{54}$ y sobre cuál debería ser la política belga a fin de garantizar la seguridad del estado en ese contexto convulso y amenazador ${ }^{55}$. Tal y como ya se ha indicado en este texto, los altos funcionarios del ministerio de exteriores belga trabajaban a partir de la convicción de que entre Francia y Reino Unido había diferencias importantes a raíz del protagonismo y la posición de Alemania en las negociaciones del nuevo Locarno ${ }^{56}$.

Tal era la situación de confusión respecto a las negociaciones que la conferencia prevista para finales del mes de julio de 1936 a celebrar en Bruselas tendría lugar finalmente en Londres, y no de la manera en la que se había previsto en un principio. Alemania, a la expectativa, retardaba las negociaciones demorando las respuestas exigidas por los aliados tras los acuerdos de marzo en Londres, y de esta forma condicionaba todo el proceso de negociación. Dadas las circunstancias, los aliados descartaron invitar al gobierno alemán a la conferencia de Bruselas. Italia, por su parte, exigió que Alemania fuese invitada como condición para su participación ${ }^{57}$. El Foreign Office, contrariado, optó por la prudencia. La conferencia a cinco de Bruselas pasó a ser una conferencia a tres en Londres con vistas a preparar una posterior conferencia de las cinco potencias locarnianas ${ }^{58}$. Dicha reunión a tres tuvo lugar el 23 de julio. Pero antes de ese día Paul-Henri Spaak hizo públicas las líneas maestras de la política exterior que pretendía aplicar.

El día 20 de julio de 1936, el nuevo ministro de exteriores belga pronunció un discurso en Bruselas ante la Unión de la Prensa Extranjera en el que, como él mismo reconocía, abordaba en público por primera vez la política exterior ${ }^{59}$. Dos frases en los primeros párrafos de la alocución no dejaban lugar a la duda sobre las intenciones del ministro:

Je voudrais que la politique étrangère de la Belgique soit placée résolument sous le signe du réalisme [...] Je ne veux qu'une chose: une politique étrangère exclusivement et intégralement belge ${ }^{60}$.

54. LANGEnhove, "Etat de la situation international», 15/06/1936, Fonds Locarno 11.115, ADB.

55. Langenhove, "Note sur la polítique à suivre en vue de garantir notre sécurité», 07/07/1936, Fonds Locarno 11.115, ADB.

56. CARTIER DE MARChiEnNe, "Les pourparlers de Bruxelles au sujet d'un nouveau Locarno», 11/07/1936, Fonds Locarno 11.115, ADB, p. 1.

57. Chastel, Télégramme No30, Roma, 12/07/1936, Fonds Locarno 11.115, ADB.

58. Cartier de Marchienne, «Notes entrevue avec M. Eden», 16/07/1936, Fonds Locarno 11.115, ADB.

59. Paul-Henri SPAAK, «Discours prononcé le 20 Juillet 1936, à l'Union de la Presse Etrangère», 22/07/1936, Fonds Locarno 11.115, ADB, p. 1.

60. Ibid., p. 2. 
Con esta toma de posición, Spaak abandonó todo viso de internacionalismo en la política exterior belga y sorprendió con un discurso sobre cuyo contenido solo estaba al corriente el primer ministro, Paul Van Zeeland. La alocución implicaba el anuncio de un brusco cambio de orientación de la política de un gobierno en cuya declaración gubernamental de 1936 postulaba el refuerzo de la seguridad colectiva y el respeto por la asistencia mutua ${ }^{61}$. El discurso, por lo tanto, fue un toque de retirada de la primera línea diplomática en toda regla. Supuso el inicio del proceso que iba a llevar a la diplomacia belga a declarar su status de neutralidad ya en 1939, tras lograr la liberación de sus compromisos internacionales derivados de los pactos que había firmado tras el final de la I Guerra Mundial.

\section{EL DISCURSO DEL REY LEOPOLDO III}

En la Conferencia de Londres del 23 de julio de 1936 se impusieron las tesis británicas para la negociación con Alemania. Se iniciaron los preparativos para una conferencia a cinco, prevista inicialmente para el mes de octubre. El Reino Unido tomó la iniciativa en el proceso del lado de las potencias democráticas. Italia y Alemania aceptaron la invitación británica para participar en dicha conferencia ${ }^{62}$.

En Francia no estaban satisfechos con el papel jugado por Bélgica en las conversaciones que se habían desarrollado desde el mes de marzo. El embajador francés en Bruselas, Jules Laroche, fue recibido por Van Zeeland el 30 de julio al objeto de dialogar sobre los resultados de la Conferencia de Londres ${ }^{63}$. El primero aseguró a su ministro de exteriores que Van Zeeland le había comunicado que la política exterior belga no había cambiado respecto a lo que él mismo había declarado a Delbos y Blum durante las reuniones que se habían mantenido para tratar la denuncia de Locarno ${ }^{64}$. Sin embargo, en el Quai d'Orsay, tal y como habían percibido los altos funcionarios del Ministerio de Asuntos Exteriores belga, preocupaban las declaraciones de Spaak. Laroche explicó a Delbos que había presionado a Van Zeeland sobre este particular. Había expuesto que ciertas frases del discurso daban pie a sostener que el gobierno belga no aceptaría la cláusula de asistencia inscrita en el Tratado de Locarno —en vigor en virtud de los acuerdos de Londres de 19 de marzo de 1936- y de ser así esta tesis era contraria a los principios de seguridad colectiva y asistencia mutua que la propia Bélgica decía respetar $^{65}$. Laroche puso de relieve ante Van Zeeland las contradicciones del discurso

61. Bulletin Périodique de la Presse Belge $\mathrm{N}^{\circ}$ 123, París, 2/09/1936, BNF, pp. 4-5. http://gallica.bnf.fr/ ark:/12148/cb32732708n/date, fecha de consulta 16/6/2015.

62. "Denonciation de Locarno", 3/11/1936, Fonds Locarno 11.115 A, ADB, p. 1.

63. LAROChe, "Rapport T. N528 bis, 529", 30/07/1936, Fonds Marcel-Henri Jaspar, I 226-1923, AGR.

64. Ibid., p. 3.

65. Ibid., p. 4 
de Spaak, y le recordó que, más allá de las mismas, los acuerdos de Londres seguían vigentes. El primer ministro belga salió del paso como pudo. Reconoció explícitamente las contradicciones en las que incurría el discurso de su ministro, aunque se mantuvo firme en la idea de seguir la línea marcada por su titular de exteriores ${ }^{66}$.

Los franceses confirmaron que la relación con su aliado belga había cambiado. Al encargado de negocios en la embajada de Francia en Bruselas, Armand Gazel, le pareció pertinente redactar un informe, dirigido al ministro Delbos, sobre las relaciones entre ambos países, puesto que, a su juicio, la información de la embajada de los últimos dos años había señalado el declive de la amistad franco-belga ${ }^{67}$. Argumentó para justificar esta percepción razones de orden económico — cualquier medida restrictiva tomada por Francia en el ámbito comercial afectaba a la economía belga, dada la estrecha relación entre ambos países-; de orden político —en Bélgica no había gustado nada el pacto franco-soviético de 1935, por considerarlo una fuente de conflicto-; y de orden estratégico internacional — según Gazel en Bélgica se pensaba que los franceses no dudarían en atravesar el país para atacar a Alemania en el caso de tener que acudir en ayuda de los rusos- Aprensiones que, según lo recogido en el informe, habían aumentado desde que la guerra civil española había generado posibilidades de conflicto internacional. La situación preocupaba al encargado de negocios porque percibió que los apoyos franceses en la política y la sociedad belgas se habían deteriorado. Entre los partidos políticos, siempre según el punto de vista de Gazel, la corriente de opinión no era en general favorable a los intereses franceses. Informó de que solamente entre comunistas y socialistas se podía contar con apoyos firmes. A continuación, hizo una referencia específica a las personalidades que se implicaban directamente en la elaboración y aplicación de la política exterior. Sobre el secretario del Ministerio de Asuntos Exteriores, Fernand Van Langenhove, afirmó que era más anglófilo que francófilo, aunque lo describió como cortés y objetivo en el cumplimiento de sus responsabilidades. Sobre el director de política, el barón Van Zuylen, dijo que era netamente anglófilo y que desconfiaba de la política francesa. En este sentido dio por confirmadas sus tendencias neutralistas y su preferencia por la política británica.

En otro orden de cosas, afirmó que fue Van Zuylen la persona que colaboró con Spaak en la redacción de su discurso del 20 de julio. Sobre este último su juicio denotó desconfianza. Lo tildó de ambicioso y aseguró que cuando Van Zeeland se retirase del gobierno para pasar a presidir "La Banque National» sería Spaak el encargado de encabezar el gabinete. Una perspectiva incierta para los intereses franceses, por tratarse de una personalidad política poco fiable ${ }^{68}$. El resto del gabinete tampoco insuflaba ánimos a Gazel. Estaba convencido de que Van Zeeland daba preferencia al Reino Unido, de

\footnotetext{
66. Ibid.

67. GAZEL, "Rapport No 692 (1)», 11/08/1936, Fonds Marcel-Henri Jaspar, I 226-1923, AGR.

68. Ibid., p. 408.
} 
que la influencia política del socialista Emile Vandervelde, entonces ministro de salud pública, estaba en pleno declive y de que los flamencos del gabinete eran partidarios de la política de independencia. Su reflexión final sobre el gabinete gubernamental estableció que este no quemaría los puentes con Francia, dada la amenaza alemana, pero que evitaría toda medida y actitud que pudiese valerle el reproche de ser el remolque de este estado. Concluyó que en la política belga las aspiraciones neutralistas y nórdicas de los flamencos se reencontraban con el "realismo» —entendido como Realpolitik - que preconizaban los políticos de las nuevas generaciones en materia de política exterior y con una búsqueda secular del equilibrio entre París, Londres y, a ser posible, Berlín. Una línea en la que también se movería el monarca, Leopoldo III, según las inferencias hechas por Gazel a partir de las informaciones que recibía de sus fuentes. Afirmó que le habían asegurado que Leopoldo era partidario de fortificar la frontera sur "dans un souci de juste équilibre» ${ }^{69}$.

Si se contrasta este informe del encargado de negocios francés en Bruselas con la documentación interna del Ministerio de Asuntos Exteriores de Bélgica se constata que los juicios expuestos en el documento sobre la perspectiva de los intereses franceses en la acción exterior belga son certeros. La perspectiva de que dichos intereses fuesen a contar con el respaldo belga en la renegociación de Locarno era muy pobre, por no decir nula. Tal y como Laroche y el propio Gazel percibieron, Bélgica cambiaba su proceder en materia de política exterior.

En el servicio diplomático belga se estaba al corriente de las reflexiones francesas. En una reunión entre Spaak y miembros destacados de las principales embajadas belgas en el exterior, la cual tuvo lugar el 4 de agosto al objeto de empezar a preparar la conferencia a cinco, el Conde de Kerchove, embajador en París, aseguró que el Quai d'Orsay sabía de la política que Bélgica perseguía. Además aseguró que el gobierno francés había constatado que Francia sufría entre la opinión pública belga una seria pérdida de crédito $^{70}$. En esa misma reunión, Spaak propuso una discusión con sus funcionarios en la que, analizando los posibles escenarios de conflicto en Europa, se pudiese establecer una línea de actuación para las negociaciones de Locarno. Tenía las ideas claras. Dialogó con sus funcionarios sobre las relaciones con Francia derivadas de Locarno. Expuso que, en su opinión, la mejor garantía que Bélgica podía ofrecer a Francia era que esta no tuviese que enviar sus tropas para defender la frontera belga, por lo tanto tenía que desarrollar una política que impidiese a Alemania atravesar Bélgica. Un compromiso que el ministro consideró proporcionado a los medios belgas.

En esa línea de conducta también se debatió sobre la posición a tomar en el caso de que se iniciase una guerra en el Este, entre Alemania y la Unión Soviética, que llevase a Francia a movilizar su ejército para atacar a la primera. Van Langenhove, también

69. Ibid., p. 410.

70. "Réunion diplomatique», 4/08/1936, 11.179 (3), ADB, p. 6. 
presente en el encuentro, afirmó de manera tajante que se rechazaría la petición de atravesar el territorio belga ${ }^{71}$. Dados los argumentos que se estaban exponiendo, el conde de Kerchove recordó que Bélgica estaba todavía ligada a los compromisos de Locarno. Si se desligaban de manera unilateral parecería una traición a Francia. Consideró que solamente el fracaso de las conversaciones a cinco llevaría a la libertad de acción de Bélgica. Spaak lo corrigió. En ese caso Francia podría poner sobre la mesa los acuerdos de Londres del 19 de marzo $^{72}$ —Laroche lo hizo en su reunión con Van Zeeland, a la que me he referido unas líneas más arriba y que tuvo lugar unos días antes, el 30 de julio-.

Spaak se mostró, entonces, dispuesto a entablar conversaciones de carácter militar con Alemania. Había que buscar el equilibrio con todas las grandes potencias, siendo la fórmula ideal un pacto como Locarno, pero con la garantía como beneficio único de Bélgica. Y todo ello con un discurso diáfano en el que, en palabras de Spaak, "il faudrait éviter le mot "neutralité" et le remplacer par celui "d'independence” ${ }^{73}$.

Vista la incierta situación de unas negociaciones sobre las que era prácticamente imposible hacer previsiones, Spaak concluyó que lo mejor que se podía hacer era seguir esperando a ver cómo se desarrollaban los acontecimientos. Se habría de intervenir solamente llegado el momento que se considerase enteramente favorable ${ }^{74}$, y se debía hacer con tres objetivos en mente: liquidar lo que pudiese quedar de los acuerdos de Londres del 19 de marzo, pues eran los acuerdos que ataban a Bélgica con el moribundo Tratado de Locarno; obtener la garantía de la inviolabilidad del territorio nacional; y, en el caso de fracasar el proceso de negociación, hacer triunfar como fuese la fórmula de la inviolabilidad del territorio ${ }^{75}$.

La postura belga se mantuvo firme en las conversaciones bilaterales que se desarrollaron con los aliados de cara a preparar la conferencia. Esta, prevista inicialmente para octubre, se retrasaba ${ }^{76}$, dando lugar a intercambios constantes entre los protagonistas del proceso. El 18 de septiembre el ministro de exteriores británico, Anthony Eden, envió un memorándum a los representantes del resto de potencias locarnianas en el que expuso sus puntos de vista para iniciar las negociaciones ${ }^{77}$. La última potencia en responder fue Bélgica. Lo hizo más de un mes después, el 22 de octubre ${ }^{78}$, y no se

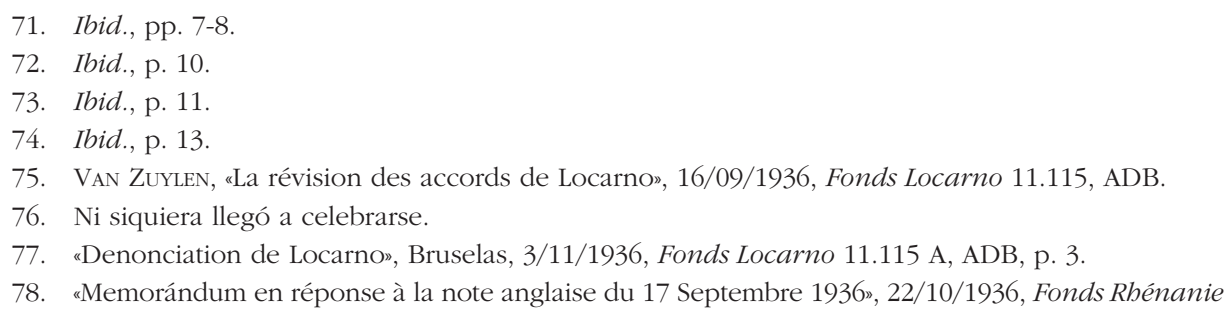
11.115, ADB. 
movió ni un ápice de los postulados, ya hechos públicos por Spaak y ratificados por el rey Leopoldo III el 14 de octubre, que se recogían en su política de independencia.

Durante la sesión del Consejo de Ministros del 14 de octubre de 1936, el monarca belga pronunció un discurso destinado a introducir un debate ministerial sobre la política de defensa. Sus palabras se hicieron públicas después de la reunión y tuvieron una importante repercusión internacional, no por lo relativo a la política de defensa sino por las referencias que hizo a la política exterior. Leopoldo recordó a sus ministros el fin último de su juramento constitucional: su compromiso para mantener la integridad y la independencia del país. Insistió en que tanto las políticas de defensa como exterior debían tener la aspiración de alejar la guerra del territorio belga. Por ello, afirmó citando a Spaak, el gobierno debía perseguir une "politique exclusivement et intégralement belge ${ }^{79}$. El monarca vinculó la política de defensa a la política exterior. Esta era la línea que el rey deseaba siguiese el gabinete en estas cuestiones.

El hecho de que el discurso de Leopoldo se enviase a las cancillerías europeas y se publicase en la prensa es la prueba de la afirmación pública de la política de independencia. A partir del día 15 de octubre, las reacciones al discurso fueron el asunto de trabajo prioritario para los colaboradores del ministro de exteriores. En los medios oficiales italianos, poco favorables al proyecto de Locarno, el discurso del rey belga fue bien recibido porque de ninguna manera suponía un impulso a las negociaciones ${ }^{80}$. En Francia, sin embargo, Delbos manifestó decepción y solicitó al embajador belga en París recibir garantías sobre la política exterior de su país ${ }^{81}$.

En Bruselas, el día después del discurso Spaak se entrevistó con el embajador francés, Jules Laroche ${ }^{82}$. Este trasladó al ministro la sorpresa de su gobierno por el discurso del monarca. Tras la conversación mantenida con Van Zeeland el 30 de julio se esperaba que Bélgica enviase una nota diplomática que definiese la actitud belga en materia de política exterior. El hecho de que Bélgica afirmase sus intenciones a través de un discurso real enviado a las principales cancillerías europeas fue interpretado por el Quai d'Orsay como un deseo de poner fin al Tratado de Locarno, a los acuerdos de Londres y a su participación en la SdN. Por su parte, Spaak se vio obligado a reducir la tensión. Argumentó que en ningún momento se barajó la opción de abandonar la SdN... nada dijo sobre los otros dos puntos que Francia reprochó, pero sobre los que ya daba por muy probable que los belgas se mantendrían firmes en sus intenciones de desligarse de sus implicaciones, tal y como estaban concebidas por el Locarno de

79. "Séance Conseil de Ministres du 14/10/1936, №26", Procès verbaux du Conseil de Ministres BE-A0510 / I 252/04, AGR, p. 294.

80. Télégramme $\mathrm{N}^{\circ} 63,15 / 10 / 1936$, Fonds Locarno 11.115, ADB.

81. Télégramme No412, 15/10/1936, Fonds Locarno 11.115, ADB

82. "Note sur l'entretien de M. Le Ministre avec l'ambassadeur de France», 15/10/1936, Fonds Locarno 11.115, ADB. 
1925 y por los acuerdos de Londres del 19 de marzo. Así, en el gobierno francés, según testimonio del ministro de exteriores británico Anthony Eden, se consideró que se daba forma a un escenario muy favorable a los intereses alemanes:

since the Germans desired nothing better than to be able to deal with other countries one by one, they were no doubt very gratified at a move such as this, for which they had not even had to ask $^{83}$.

En Londres, el propio Eden no escondió al embajador belga, el Barón de Cartier, que la opinión inglesa podría quedar impresionada de forma desfavorable por lo repentino e inesperado de la actitud de su gobierno. De hecho, la prensa británica no reaccionó favorablemente al discurso de Leopoldo. También comunicó que esta declaración tendría efectos sobre la negociación de la conferencia a cinco ${ }^{84}$. Personalmente se mostró muy sorprendido y perturbado por el discurso, y consideró desafortunado que el gobierno belga no informase con anterioridad o consultase al gobierno británico ${ }^{85}$.

Desde luego, sorprende la perturbación de Eden. Van Zeeland y Spaak ya venían defendiendo desde hacía unos meses la política de independencia en sus relaciones con sus colegas ingleses y franceses. De hecho, desde el 20 de julio, cuando Spaak comunicó por primera vez públicamente los ejes básicos de la nueva acción exterior belga, la preocupación francesa había ido en aumento. Al parecer, como la actitud belga había sido favorable a los intereses del Reino Unido frente a los intereses franceses en cuanto a cómo tratar la denuncia de Locarno por parte del gobierno alemán, a Eden ni siquiera se le pasó por la cabeza que los belgas se deslizaban conscientemente hacia la neutralidad. Es más, las palabras de Leopoldo no diferían de las de Spaak. De hecho, lo citaba literalmente. Así, la afirmación de Eden de que la postura belga anunciada por su rey iba a cambiar las negociaciones para la conferencia a cinco aparece como ridícula. Las negociaciones ya estaban condicionadas por la postura belga, y los franceses eran perfectamente conscientes de ello a finales de julio, muy poco después del discurso de Spaak.

De hecho, la actitud de Eden en su conversación con el embajador belga es desconcertante, más allá de expresar el disgusto que le generó el discurso de Leopoldo. Hizo al Barón de Cartier la misma observación que el embajador francés en Bruselas había hecho a Van Zeeland dos meses antes, es decir, que los compromisos de Locarno seguían vigentes a través de los acuerdos de Londres del 19 de marzo, y que

83. EDEn, Anthony, «Preparations for the proposed five power conference C.P. 268 (36)», 16/10/1936, The cabinet papers, TNA, p. 18, http://discovery.nationalarchives.gov.uk/details/r/D7730647, fecha de consulta 2/11/2016.

84. Télégramme N²20, Londres, 15/10/1936, Fonds Locarno 11.115, ADB

85. EDEN, Anthony «Preparations for the proposed five power conference C.P. 268 (36)», 16/10/1936, The cabinet papers, TNA, p. 15, http://discovery.nationalarchives.gov.uk/details/r/D7730647, fecha de consulta 2/11/2016. 
el discurso del rey —el embajador francés se había referido el 30 de julio al discurso de Spaak - entraba en contradicción con el contenido de los citados acuerdos. Añadió que el discurso daba munición para los aislacionistas belgas -Eden no había reparado que estos eran mayoría en los partidos políticos y puestos de responsabilidad en el gobierno y el Ministerio de Exteriores-. Y en este punto se mostró cuando menos ingenuo al protestar, porque Bélgica era el único estado que todavía no había respondido a la nota británica del 17 de septiembre, en la que se proponían los principios sobre los que renegociar Locarno. Sobre esta nota, preguntó al embajador si había de cerrarse la puerta a que Bélgica fuese de alguna manera estado garante para con Francia $^{86}$. Como ya se ha indicado en este texto, Bélgica respondió el 22 de octubre que su punto de partida para la negociación era que solo contemplaba la posibilidad de recibir garantías y no ofrecerlas ${ }^{87}$.

Contando con la ventaja de la retrospectiva, me atrevo a afirmar que la ingenuidad de Eden rayaba la incompetencia, pues el 13 de octubre, un día antes del discurso de Leopoldo III, el ministro francés de exteriores, Delbos, en una conversación con el embajador belga Kerchove quitó importancia a la cuestión de la garantía belga —entendió que los belgas no iban a ceder en este punto- para centrar las conversaciones en mantener los contactos entre los Estados Mayores —único acuerdo que sobrevivió a la derogación del pacto franco-belga de 1920, siempre con el objetivo de garantizar la resistencia en el caso de un ataque alemán ${ }^{88}$. Por lo tanto, la reacción británica demostró una flagrante falta de atención a los movimientos políticos que ejecutaba uno de sus aliados, tanto es así que en la prensa alemana llamó la atención la reacción británica al discurso. Al respecto se dijo que vino a exponer y confirmar ideas semejantes a las que había desarrollado ya el ministro de exteriores en su discurso de julio ${ }^{89}$.

En esta línea argumental se emplazó también la respuesta belga a las primeras reacciones de Eden. El embajador belga en Londres, el Barón de Cartier, envió al Foreign Office un memorándum en el que defendió que la argumentación política esgrimida por el monarca no tuvo nada de inesperado. Añadió que indicaciones de esa orientación ya habían sido hechas públicas por el discurso de Spaak del 20 de julio. Y, quizá lo más importante, que había sido ya objeto de discusión en numerosos debates con representantes diplomáticos franceses y británicos, «in particular with Messrs. Eden and

86. Ibid., p. 16.

87. "Memorándum en réponse à la note anglaise du 17 Septembre 1936», 22/10/1936, Fonds Rhénanie 11.115, ADB.

88. Kerchove, "Le nouveau Locarno, les conversations de Genève et les relations franco-belges. Entretien avec M. Delbos", 13/10/1936, 11.179 (3), ADB.

89. "La réaction allemande au discours du Roi», 16/10/1936, Fonds Rhénanie 11.115, ADB, p. 5. 


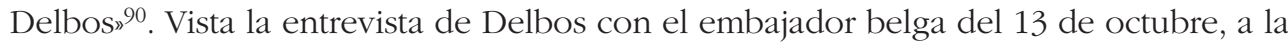
que ya he aludido, puedo afirmar que Eden no queda en buen lugar en todo este asunto.

El 17 de octubre Eden, que se encontraba en París, se reunió con el embajador belga en Francia, el conde de Kerchove, que disculpó las ausencias de Van Zeeland y Spaak, algo que no cayó bien a ministro británico pues deseaba entrevistarse con ellos ya que por esa razón se había organizado el encuentro ${ }^{91}$. En esta reunión Eden fue duro con Kerchove. Reprochó las formas que rodearon al discurso y le recordó que en el mes de julio Van Zeeland expresó el deseo de reforzar los lazos de solidaridad entre Francia, Reino Unido y Bélgica, en vista de la celebración de una nueva reunión locarniana ${ }^{92}$. Eden no creía que el discurso se correspondiese con lo declarado por Van Zeeland durante la Conferencia de Londres del 23 de julio. También añadió que en ese encuentro se acordó que no se llevarían a cabo acciones unilaterales, y que solo se tomarían decisiones en común, de nuevo algo que no casaba con el contenido del discurso del rey. La tormenta dialéctica desatada por Eden siguió con el reproche de que el discurso había puesto a Francia al mismo nivel que Alemania como potencial agresor, algo que era percibido en este país como un notable debilitamiento de la solidaridad franco-belga ${ }^{93}$. Llegado a este punto preguntó directamente a Kerchove si el nuevo estatus internacional deseado por Bélgica era la neutralidad ${ }^{94}$, y preguntó si Bélgica tenía intención de entablar conversaciones en paralelo con Alemania, ante lo cual Kerchove "made an express reserve»" ${ }^{95}$.

Los ecos de las palabras de Leopoldo llegaron al Este. En Polonia, el periódico Gazeta Polska calificó el discurso de simbólico porque implicaba el final del sistema de seguridad colectiva y el renacimiento de la neutralidad ${ }^{96}$. En esta línea se expresó también explícitamente el ministro de asuntos exteriores alemán, Von Ribbentrop, cuando se entrevistó con el embajador belga en Berlín, el Vizconde Jacques Davignon. El primero trasladó al embajador que Alemania podía garantizar la neutralidad de Bélgica y de los

90. EDEN, Anthony, «Preparations for the proposed five power conference C.P. 268 (36)», 16/10/1936, The cabinet papers, TNA, p. 19. http://discovery.nationalarchives.gov.uk/details/r/D7730647, fecha de consulta, 2/11/2016.

91. EDEn, Anthony, "Preparations for the proposed five power conference C. P. 284 (36)», 26/10/1936, The cabinet papers, TNA, p. 4, http://discovery.nationalarchives.gov.uk/details/r/D7730663, fecha de consulta 2/11/2016.

$\begin{array}{ll}\text { 92. } & \text { Ibid. } \\ \text { 93. } & \text { Ibid. } \\ \text { 94. } & \text { Ibid., p. } 5 . \\ \text { 95. } & \text { Ibid. } \\ \text { 96. } & \text { "Renaissance }\end{array}$

96. "Renaissance de la neutralité», Gazeta Polska, 20/10/1936, Fonds Rhénanie 11.115, ADB. Desde Polonia se seguía de cerca la evolución de las negociaciones de Locarno por los movimientos diplomáticos y las alianzas de los franceses en el este de Europa. Para profundizar en esta cuestión véase SAKWA, George, "The Franco-Polish Alliance and the remilitarization of the Rhineland", The Historical Journal, Vol. 16, N ${ }^{\circ} 1$ (Mar. 1973), pp. 125-146, http://www.jstor.org/stable/2637919. 
Países Bajos, y añadió que respecto a Bélgica el gobierno alemán también podía dar la garantía de seguridad que anhelaba vis-à-vis de la propia Alemania, pues no había ningún obstáculo para la conclusión de una entente ${ }^{97}$.

Tal y como preveían los franceses, la situación que se había materializado a raíz del discurso del rey suponía una oportunidad para Alemania. El ministro de exteriores alemán comenzó a tratar a los belgas no como adscritos a un bloque, sino a través de conversaciones bilaterales. Les hizo las promesas que estos deseaban recibir para consolidar su retirada de la primera línea diplomática europea. La única cuestión que a esas alturas importaba al gobierno de Van Zeeland era saber en qué medida, de cara a los nuevos acuerdos a negociar, había lugar para ir más allá de la letra recogida en el Covenant ${ }^{98}$, una aspiración que descartaba por completo un nuevo Locarno, es decir, un sistema de seguridad colectiva basado en la concesión mutua de garantías en caso de agresión ${ }^{99}$.

Los contactos entre Delbos y Spaak a raíz del discurso del rey refuerzan la tesis de que Bélgica no deseaba la reconstrucción de Locarno tal y como este tratado había sido originalmente firmado. El ministro francés envió un mensaje a su homólogo belga — por mediación del embajador Kerchove- en el que le trasladó la decepción por su posición, a la par que una serie de reproches por cómo se había conducido la diplomacia de Bruselas ${ }^{100}$.

A través de su embajador en París, Spaak transmitió a Delbos que la definición de la política exterior belga competía exclusivamente a Bélgica. Tal y como se había respondido a Londres, se trasladó a Delbos que tanto el propio Spaak como el primer ministro Van Zeeland ya se habían expresado en los términos en los que lo hizo el monarca. Y ante los reproches del ministro francés sobre un enfriamiento en las relaciones franco-belgas y un acercamiento a Alemania, Spaak aceptó el primero y calificó el segundo de "fantasmagoría" ${ }^{101}$. Cierto era que no había un acercamiento hacia Alemania, en los términos en los que este implicase la búsqueda de una entente tal y como la

97. Davignon, "Locarno. La securité de la Belgique. Conversation avec M. Von Ribbentrop», 16/10/1936, Fonds Rhénanie 11.115, ADB, p. 5.

98. Uno de los párrafos del artículo 16 despertaba rechazo en la diplomacia belga. En concreto el que hacía referencia al tránsito de fuerzas armadas de uno de los miembros de la liga que acudiese a socorrer a otro miembro objeto de agresión por parte de un tercero. El texto decía así: "they will mutually support one another in resisting any special measures aimed at one of their number by the covenant-breaking State, and that they will take the necessary steps to afford passage through their territory to the forces of any of the Members of the League which are co-operating to protect the covenants of the League».

En "The Covenant of the League of Nations», http://avalon.law.yale.edu/20th_century/leagcov.asp\#art16, fecha de consulta 16/07/2017.

99. SpaAK, Paul-Henri, Doc. No 425/1, 16/10/1936, Fonds Rhénanie 11.115, ADB.

100. SPAAK, Paul-Henri, «Projet», 20/10/1936, Fonds Rhénanie 11.115, ADB.

101. Ibid., p. 2. 
había ofrecido Von Ribbentrop; pero sí que se constata a través de la documentación que se pretendía entablar un diálogo con el gobierno de Hitler para trabajar en pos del establecimiento, desde el punto de vista belga, de un equilibrio en las relaciones con las grandes potencias de forma que Bélgica no pudiese ser catalogada como la aliada de Francia.

Transmitidas las respuestas a los reproches recibidos, Spaak procedió a dar una explicación de los motivos por los que el gobierno del que formaba parte aplicaba la llamada política de independencia. Arguyó motivos externos e internos. Los primeros se redujeron a una simple frase: una situación internacional cada vez más tensa. Respecto a los segundos expuso que la obligación del gobierno era garantizar la unidad del país y que, por ello, era su responsabilidad y deber promover una política exterior que garantizase la seguridad nacional y que fuese aceptada por todos los belgas ${ }^{102}$. Por lo tanto, en lo concerniente a las garantías y explicaciones demandadas por Delbos respecto a la política exterior de Bélgica, Spaak reafirmó su voluntad de desarrollar una política de independencia de forma que su país solo conservase las obligaciones internacionales que se derivaban del Pacto de la $\mathrm{SdN}^{103}$. Respecto a la posibilidad de que Bélgica fuese garante en un nuevo pacto de seguridad occidental y respecto a la conservación de los acuerdos entre los Estados Mayores afirmó no encontrarlos deseables. No quería comprometerse en tiempos de paz. Añadió que desde un punto de vista político no creía posible un acuerdo unilateral con Francia porque sería contrario a la política de independencia y privaría a Bélgica de las ventajas obtenidas a través de la imparcialidad ${ }^{104}$.

El último mensaje que trasladó a su colega francés abordó el talón de Aquiles que la diplomacia belga tenía en su argumentario: los acuerdos de Londres de 19 de marzo de 1936, por los que los compromisos de Locarno seguían vigentes entre los aliados hasta que se concluyese la negociación de un nuevo tratado. Spaak se salió por la tangente interpretando dichos acuerdos a su manera para abrir una puerta por la que escapar de la trampa en la que ellos mismos, tal y como habían reconocido en la reunión del 4 de agosto, se habían metido al aceptar el contenido de las propuestas inglesas para afrontar la crisis renana y el proceso negociador que debía abrirse:

En ce qui concerne le présent, nous sommes encore moralement tenus de nous prêter aux consultations d'État-Major prévues dans l'Arrangement de Londres du 19 mars [...] Quand je dis «moralement tenus», je vise la situation très particulière créée par ce que les Français appellent «l'Accord de Londres» et ce que les Anglais appellent plus justement les "propositions de Londres»"105.

102. Ibid.

103. Ibid., p. 3 .

104. Ibid., p. 5.

105. Ibid., p. 6. 
Spaak manipuló el lenguaje, lisa y llanamente, para encontrar una rendija a través de la que meter la cuña de la política de independencia y así poder desarrollarla sin que nadie pudiese juzgar la acción belga como infiel a los compromisos.

El 24 de octubre se envió al cuerpo diplomático una circular que contenía las instrucciones en vista de coordinar la acción para la orientación de la política exterior. La consigna no pudo ser más clara, pues se afirmaba que de cara a la revisión de los acuerdos de Locarno el discurso del rey definía las ideas en las que se inspiraría el gobierno para las próximas negociaciones ${ }^{106}$. A nivel diplomático no había dudas: la política de independencia era una realidad en curso. El objetivo a corto plazo era que fuese reconocida por las principales potencias europeas.

En ese sentido, la propia dinámica de las políticas exteriores británica y francesa, daban esperanzas a los anhelos belgas. El barón Van Zuylen informó a Spaak sobre los intereses británicos según informaciones transmitidas por el general Van den Bergen, miembro del Estado-Mayor. Este había asistido a una cena con el embajador británico en Bruselas, Esmond Ovey, y con el jefe del servicio de operaciones militares británicas, el Mayor Clark ${ }^{107}$. Según la versión del Mayor, el embajador afirmó que Bélgica podía contar con seguridad con el apoyo militar de Reino Unido en caso de una agresión, incluso si no había ningún documento oficial que lo prometiese ${ }^{108}$. Le comunicó que Reino Unido no se interesaría por ningún acontecimiento que tuviese lugar en el Este o el Sur de Europa, incluido el Mediterráneo, afirmando que sus intereses vitales pasaban por el Atlántico ${ }^{109}$.

La conclusión que sacó Van Zuylen de semejante discurso, dado lo que preocupaba en Bruselas el pacto franco-soviético de 1935, fue que esta información indicaba a las claras la extensión de los compromisos belgas en virtud del Covenant, concretamente su artículo 16. Afirmó que no se podía concebir que Bélgica fuese a estar sujeta a obligaciones más estrictas que las de Reino Unido. Por lo tanto, en el caso de que Francia reclamase un derecho de paso por el territorio belga para acudir en auxilio de uno de sus aliados en el Este, el gobierno belga tendría el derecho de rechazarlo ${ }^{110}$. Si Reino Unido no se interesaba por lo que había de suceder en el Este o en el Sur de Europa... ¿por qué iba a hacerlo Bélgica?

Por lo tanto, a lo largo del mes de noviembre de 1936, los belgas afirmaron sus intenciones de cara a las negociaciones de Locarno y se mantuvieron firmes en sus posiciones al respecto: Van Zeeland declaró en sede parlamentaria el 2 de diciembre que

106. "Circulaire d'information confidentielle No13", 24/10/1936, Fonds Rhénanie 11.115, ADB, p. 1.

107. VAn ZuYlen, "Note pour M. le Ministre», 22/10/1936, Fonds Rhénanie 11.115, ADB.

108. Ibid., p. 1 .

109. Ibid.

110. Ibid., p. 2. 
el gobierno belga no daría garantías y que se comprometería a defender su territorio ${ }^{111}$. Así las cosas, lo que más preocupaba a los británicos eran las posibles fricciones de los belgas con los franceses y con sus propios intereses. Temían que estas llevasen a los primeros a retirarse de las negociaciones y que esta circunstancia pudiese desembocar en un acercamiento de Bélgica a la órbita alemana ${ }^{112}$. Por ello, Eden se mostró partidario de continuar la cooperación entre los tres estados aliados, aunque asumió que había de hacerse a partir de parámetros que tuviesen en cuenta los límites impuestos por los belgas y lidiando con el descontento francés ${ }^{113}$. Asumidas esas nuevas condiciones, se trataba de negociar el acceso al territorio belga en caso de agresión. Sobre todo en lo que concernía al permiso de sobrevolar su espacio aéreo ${ }^{114}$, dado que los belgas se mostraban muy firmes en su interpretación del artículo 16 del Covenant y afirmaban que tenían el derecho de reservarse la posibilidad de prohibir el acceso y el tránsito de los ejércitos de otros miembros de la SdN.

\section{EL RECONOCIMIENTO INTERNACIONAL DE LA POLÍTICA DE INDEPENDENCIA}

El 23 de diciembre de 1936, el diario belga Le Vingtième siècle daba por sentado que Locarno no iba a renegociarse. Por lo tanto, afirmó en sus páginas que Bélgica podía considerarse como desligada del pacto renano y de sus secuelas. Defendía la necesidad de definir un status internacional para el país que pasase por recibir garantías sin darlas ${ }^{115}$, exactamente el objetivo por el que trabajaba el gobierno Van Zeeland.

Poco después de esta toma de posición, concretamente el 30 de enero de 1937, Hitler pronunció un discurso ante el Parlamento alemán para conmemorar el cuarto aniversario de la toma del poder por los nacional-socialistas ${ }^{116}$. El discurso fue seguido con mucha expectación en Bélgica, pues se esperaba que el canciller alemán hiciese alguna referencia al país. Efectivamente, Hitler expuso que, en lo que tocaba a Bélgica

111. Eden, Anthony, "Position of Belgium and the proposed five power Conference C.P. 332 (36)", 5/12/1936, The cabinet papers, TNA, p. 1. http://filestore.nationalarchives.gov.uk/pdfs/small/cab-24-265-CP-332-5. pdf, fecha de consulta 2/11/2016.

112. Ibid., p. 2.

113. En un encuentro que reunió a Léon Blum, Yvon Delbos, P.-H. Spaak y Paul Van Zeeland, el primero les dijo a los belgas que el discurso del rey había sido un golpe duro e inesperado para Francia. "Conversation du 13/12/1936», Fondos Paul-Henri Spaak, PHS-11 1936-1937, Doc. 0191, Historical Archive of the EU (HAEU). http://archives.eui.eu/en/fonds/187973?item=PHS-01-15, fecha de consulta 19/12/2016.

114. EDEN, Anthony, "Position of Belgium and the proposed five power Conference C.P. 332 (36)", 5/12/1936, The cabinet papers, TNA, p. 5. http://filestore.nationalarchives.gov.uk/pdfs/small/cab-24-265-CP-332-5. pdf, fecha de consulta 2/11/2016.

115. Bulletin Périodique de la Presse Belge No125, París, 17/03/1937, BNF, p. 1. http://gallica.bnf.fr/ ark:/12148/bpt6k64198838.item, fecha de consulta 16/6/2015.

116. Ibid., p. 4. 
y Países Bajos Alemania estaba decidida a reconocer a ambos estados como territorios neutrales y a ofrecer garantías al respecto ${ }^{117}$. Esta declaración de Hitler fue el punto de partida de una negociación entre ambos estados para que Alemania reconociese el nuevo status internacional al que aspiraba Bélgica, un camino difícil que a principios de 1937 presentaba obstáculos que la diplomacia belga se había propuesto salvar.

Insistiendo en la línea política seguida a lo largo de 1936, Spaak se apuntó un primer éxito cuando en Gran Bretaña el debate sobre Locarno basculó hacia la cuestión belga. La idea de garantizar la integridad belga escaló puestos en la agenda política británica y encontró su lugar en el debate público sobre las negociaciones de Locarno. Hubo quien pidió abiertamente que el objetivo inmediato de la política británica en Europa Occidental fuese la garantía internacional de la integridad territorial belga. Se argumentó que Gran Bretaña y Francia ya la habían dado — a través del viejo Locarno y de los acuerdos de Londres de marzo de 1936-, y que la novedad a esas alturas de marzo de 1937 era que Hitler había declarado que Alemania estaba también por la labor de darla118.

En este caso se compraba el argumento ofrecido por Spaak para vencer la resistencia francesa a la retirada de los belgas como garantes en un nuevo pacto. Es decir, que Bélgica podía contestar a las objeciones francesas con el compromiso de que, bajo cualquier circunstancia, el país resistiría un ataque dirigido a Francia a través de su territorio. Los belgas podían argumentar que su mejor contribución al mantenimiento de la paz en Europa se haría a través del refuerzo de sus defensas ${ }^{119}$. El argumento de Spaak y de su servicio de acción exterior había calado en el debate público británico sobre la cuestión de Locarno.

Entretanto, las negociaciones entre las potencias signatarias del tratado continuaban al objeto de lanzar la conferencia a cinco que se había previsto para octubre de 1936, y que ya bien entrado 1937 todavía no se había celebrado. Evidentemente la nueva posición belga cambió la orientación de las negociaciones. El 22 de marzo el rey Leopoldo se entrevistó en la embajada belga de Londres con Eden. Este no había terminado de encajar el viraje belga. Manifestó que los británicos temían que Bélgica pudiese inclinarse hacia el lado alemán, y afirmó que veían con miedo el rexismo ${ }^{120}$, al que calificó de fascista, pues consideraba a este movimiento político el canal a través

117. Télégramme $\mathrm{N}^{\circ} 7,30 / 01 / 1937,11.179$ (3 bis), ADB.

118. "Belgian Pact First", Yorkshire Post, 10/03/1937, Fonds Locarno, 11.115, ADB.

119. Ibid.

120. El rexismo era un movimiento político que apelaba a la renovación moral de la sociedad belga de acuerdo a los postulados de la Iglesia Católica para conformar una sociedad corporativista y sin democracia. Así, el Partido Rexista (REX), creado por Léon Degrelle, se presentó a las elecciones legislativas del 24 de mayo de 1936 como una alternativa política autoritaria de último recurso contra las taras imputadas al régimen de partidos y a la democracia parlamentaria. Sobre Léon Degrelle y el rexismo véase DI MURO, Giovanni, Léon Degrelle et l'aventure rexiste (1927-1940), Bruselas, Luc Pire Editions, 2005. 
del cual Bélgica quedaría englobada en el grupo de estados autoritarios y en manos alemanas $^{121}$. El rey se vio obligado a justificar la política exterior de Spaak. Aseguró que el deseo belga era tratar de mantener el equilibrio en las relaciones con los países de su entorno. Leopoldo no escondió el miedo a un «nuevo $1914{ }^{122}$, que actuaba como principio director de la nueva política exterior. A pesar de que Eden aseguró al monarca belga durante esa misma reunión que «une guerre est inevitable un jour»"23, a finales del mes de marzo franceses y británicos asumieron que los belgas no iban a cambiar de idea y aceptaron que el paso de desligar a Bruselas de sus obligaciones de Locarno había de darse ${ }^{124}$.

En un memorándum firmado por el ministro Yvon Delbos, enviado por el gobierno francés al gobierno británico el 20 de marzo, se exponía que lo que más preocupaba al gobierno belga no era recibir garantías inmediatas por parte de las grandes potencias como parte de Locarno, sino verse liberado de las obligaciones de asistencia que él mismo había asumido, particularmente a través de los acuerdos de 19 de marzo de 1936. Por ello, continuaba el memorándum, una declaración de ambos gobiernos sería sin duda suficiente para dar al gobierno belga la inmediata satisfacción que requería ${ }^{125}$.

La respuesta de Eden a los franceses llegó el día 24 de marzo. Acordaron con el embajador francés que la mejor manera de progresar en el asunto era que el gobierno francés preparase un borrador de la declaración que se dirigiría al gobierno belga ${ }^{126}$. Este acuerdo fruto de la reunión de ambos se completó con un memorándum que el Foreign Office envió al Quay d'Orsay, en el que expresaba cómo se debía proceder de cara a la elaboración de la declaración y a la escenificación que la acompañaría. Se posicionó por una declaración conjunta, a realizarse de acuerdo con el gobierno belga y que debería presentarse lo antes posible. Argumentó también que debía exigirse a Bruselas una serie de compromisos: mantener sus fuerzas armadas y sus sistemas de defensa en un estado de máxima eficacia; emplear todas sus fuerzas armadas para defender sus fronteras en caso de una invasión, así como para evitar que Bélgica fuese usada como paso o base de operaciones con propósitos de agresión; y continuar siendo miembro de la SdN y asumiendo las obligaciones del Covenant ${ }^{127}$. Y todo debía llevarse a cabo de manera que no se diese la impresión de que lo que ambos

121. "Conversation du Roi avec M. A. Eden», 22/03/1937, Fondos Paul-Henri Spaak, PHS-11 1936-1937, Doc. 0194, HAEU. http://archives.eui.eu/en/fonds/187973?item=PHS-01-15, fecha de consulta 19/12/2016.

122. Ibid.

123. Ibid., p. 3 .

124. "Note sur la declaration franco-britanique et sur la declaration allemande concernant la Belgique", 23/11/1937, Fonds Locarno, 11.115, ADB, p. 4.

125. En Eden, Anthony, "Position of Belgium CP 110 (37)», 20/03/1937, The cabinet papers, TNA, pp. 2-3, http://discovery.nationalarchives.gov.uk/details/r/D7730780, fecha de consulta 2/11/2016.

126. Ibid., p. 3.

127. Ibid., p. 4. 
gobiernos estaban concediendo a Bélgica implicase de alguna forma la suspensión o el fracaso de las negociaciones a cinco ${ }^{128}$.

Londres lanzó otra vez una ronda de negociación a tres para tratar las implicaciones de los acuerdos de marzo de 1936. A principios del mes de abril Spaak se mostraba optimista respecto al curso de estas negociaciones, e informaba en el Consejo de Ministros sobre la inminencia de una declaración por parte de las potencias signatarias de Locarno, por la que se liberaría a Bélgica de la carga de la garantía que tenía comprometida sobre las fronteras de Francia y Alemania ${ }^{129}$. Así pues, el día 24 de abril, en una declaración conjunta, Reino Unido y Francia desligaban a Bélgica, por petición expresa de esta, de las obligaciones del Tratado de Locarno de 1925 y de los acuerdos tripartitos de Londres de marzo de 1936, manteniendo al mismo tiempo las garantías de ambos países respecto a la seguridad y la integridad del territorio belga ${ }^{130}$. Por lo tanto, más allá del Pacto de la SdN, Bélgica no quedaba sometida a ninguna otra obligación de orden internacional ${ }^{131}$.

Así, Paul-Henri Spaak pudo anunciar el reconocimiento franco-británico de la política de independencia ante el Parlamento el 29 de abril de 1937. Un acontecimiento que, en palabras del propio Spaak, significaba para Bélgica el cierre de la era de los acuerdos militares ${ }^{132}$. El significado de esta declaración y de que para nada implicaba un deterioro en las relaciones entre los tres países se quiso reforzar con las visitas a Bruselas de los ministros de asuntos exteriores de Reino Unido, Anthony Eden, y de Francia, Yvon Delbos. Estas tuvieron lugar los días 26 y 27 de abril y los días 20 y 21 de mayo, respectivamente.

La política de independencia belga, que ya era una realidad en el marco de la política europea, se trasladó al marco del Consejo de la SdN por parte de los ministros de exteriores francés y británico, Delbos y Eden, a finales de mayo de $1937^{133}$. Por lo tanto, el siguiente movimiento de la diplomacia belga era conseguir una declaración similar por parte del gobierno alemán.

El discurso de Hitler pronunciado el 30 de enero de 1937 ante el Reichstag fue el punto de partida para las negociaciones entre ambos estados. El día 4 de febrero el barón Von Neurath comunicaba al embajador belga en Berlín, el Vizconde Davignon, cómo se debían interpretar las palabras de Hitler. Explicó que se trataba de una

128. Ibid., p. 5.

129. "Séance du Conseil de Ministres du 6/04/1937, №59", Procès verbaux du Conseil de Ministres BE-A0510 / I 252/04, AGR, p. 105.

130. Circulaire d'information personnelle $\mathrm{N}^{\circ}$ 5: "Nouveau statut international de la Belgique. Note Britanique et Française du 24 Avril 1937», 24/04/1937, Fonds Locarno, 11.115, ADB.

131. Ibid., p. 8.

132. Séance du jeudi 29 Avril 1937 de la Chambre de Représentants, Fonds Locarno, 11.115, ADB, p. 509.

133. "Circulaire d'information $\mathrm{N}^{\circ}$ 42: Nouveau statut international de la Belgique. Communication au Conseil de la Societé de Nations", 05/1937, Fonds Locarno, 11.115, ADB. 
oferta válida para cualquier posible escenario que se diese tras las negociaciones de Locarno ${ }^{134}$. Davignon respondía el día 8 de febrero expresando la satisfacción belga por poder colaborar desde ese momento con Alemania ${ }^{135}$, y trasladó que de cara a esa colaboración Bélgica partía de la base de que la palabra «neutralidad» en boca de Hitler hacía referencia a la política de independencia y de imparcialidad que el gobierno belga estaba desarrollando ${ }^{136}$. Por consiguiente, esperaban lograr una garantía del Reich de carácter unilateral e incondicional que no implicase ninguna contrapartida y que, además, fuese independiente de un eventual pacto de seguridad occidental que se pudiese concluir ${ }^{137}$.

Tras la confirmación de la declaración franco-británica y la constatación de que las negociaciones locarnianas estaban completamente estancadas, los belgas pensaron que era deseable dar salida a las ofertas puestas por Hitler encima de la mesa y completar la declaración franco-británica con una declaración alemana. Consideraron que podían plantear al gobierno alemán la posibilidad de tratar la cuestión belga disociada del problema general de la seguridad europea, para hacer de la misma una primera etapa en las negociaciones de cara a establecer un acuerdo general ${ }^{138}$. Por lo tanto, se entablaron contactos oficiosos entre ambas capitales para trabajar en el acuerdo que diese forma a una declaración que emitiría el gobierno alemán sobre la base de la oferta realizada por Hitler el 30 de enero, y que se formularía en términos análogos a los de la declaración franco-británica ${ }^{139}$.

Se alcanzó un principio de acuerdo sobre la cuestión el 18 de septiembre de $1937^{140}$, y cuando las negociaciones estaban lo suficientemente avanzadas como para pensar que no se torcerían Spaak informó a sus colegas francés y británico del estado de los contactos con el gobierno alemán. Primero lo hizo a través de los embajadores en Bruselas ${ }^{141}$, asegurándoles al mismo tiempo que escribiría él mismo a sus homólogos para trasladarles estas informaciones ${ }^{142}$. Envió las cartas el día 10 de octubre ${ }^{143}$.

134. "Circulaire d'information confidentielle $\mathrm{N}^{\circ} 11$ : Déclaration du Gouvernement allemand sur l'inviolabilité et l'integrité de la "elgique"”, 11/10/1937, Fonds Locarno, 11.115, ADB, p. 23.

135. Ibid.

136. "Note sur la declaration franco-britanique et sur la declaration allemande concernant la Belgique", 23/11/1937, Fonds Locarno, 11.115, ADB, p. 7.

137. Ibid., p. 8 .

138. Ibid.

139. Ibid., p. 9 .

140. "Statut de la Belgique», Aperçu Hebdomadaire, 9/10/1937, 11.179 (3 bis), ADB, p. 1.

141. "Entretiens du Ministre avec l'ambassadeur d'Anglaterre et l'ambassadeur de France», 6/10/1937, 11.179 (3 bis), ADB.

142. "Entretiens du Ministre avec l'ambassadeur d'Anglaterre et l'ambassadeur de France», 9/10/1937, 11.179 ( 3 bis), ADB.

143. Cartas de Spaak a Eden y Delbos, 10/10/1937, 11.179 (3 bis), ADB. 
Las negociaciones entre los gobiernos alemán y belga desembocaron en un texto que el gobierno alemán entregó al embajador Davignon el 13 de octubre de $1937^{144}$. Ese mismo día la declaración se hizo pública a través de la prensa. En ella, el gobierno alemán precisaba su actitud desde ese mismo momento respecto al estado belga. Teniendo en cuenta las propias declaraciones del ejecutivo belga respecto a la política de independencia que pretendía desarrollar y a su determinación de defender sus fronteras contra toda agresión, así como de evitar que su territorio fuese utilizado para llevar a cabo una agresión, el gobierno del Reich constataba que la inviolabilidad y la integridad de Bélgica eran de interés común para las potencias occidentales. Por ello, confirmaba su determinación de no menoscabar esta inviolabilidad y esta integridad bajo ninguna circunstancia y de respetar en todo momento el territorio belga, excepto en el caso de que Bélgica proporcionase ayuda militar a un tercero implicado en un conflicto con Alemania. Concluía la declaración asegurando que el gobierno alemán estaba preparado para, al igual que los gobiernos británico y francés, acordar asistencia a Bélgica llegado el caso de un ataque o una invasión ${ }^{145}$.

Bélgica y Alemania consideraron esta declaración al mismo nivel que la efectuada por Reino Unido y Francia el 24 de abril, e indicaron que había que situarla en el marco de los esfuerzos desplegados para la realización de un nuevo pacto de seguridad occidental ${ }^{146}$. Por lo tanto, a finales de 1937 se dibujó para Bélgica un panorama internacional que colmaba las aspiraciones políticas de su gobierno: su nueva posición en el tablero europeo había sido reconocida por los principales actores del drama. Y esta circunstancia significó la extinción de todas las oportunidades que a esas alturas de los años 30 pudiese tener todavía el sistema de seguridad colectiva que había compuesto el marco en el que las relaciones internacionales se habían desarrollado durante los últimos 12 años.

\section{COnClusiones}

El 24 de abril de 1937, día en que se hizo pública la declaración franco-británica, Bélgica se desembarazó de lo que su gobierno concebía como una molesta hipoteca dadas las tendencias aislacionistas y neutralistas presentes en su panorama político interno y fruto del miedo a que el país pudiese verse arrastrado a un conflicto europeo.

144. "Note sur la declaration franco-britanique et sur la declaration allemande concernant la Belgique", 23/11/1937, Fonds Locarno, 11.115, ADB, p. 9.

145. Declaración disponible en Anexo B, de 13/10/1937, a la "Circulaire d'information N59: Déclaration du Gouvernement allemand sur l'inviolabilité et l'integrité de la Belgique», 11/10/1937, Fonds Locarno, 11.115, ADB.

146. "Note sur la declaration franco-britanique et sur la declaration allemande concernant la Belgique", 23/11/1937, Fonds Locarno, 11.115, ADB, p. 10. 
Así, el marco de política internacional ideal para el gobierno de Bélgica, que se perseguía oficialmente desde julio de 1936, se terminó de dibujar el 13 de octubre de 1937, día en que se publicó la declaración del gobierno de Reich por la que este se declaraba dispuesto a respetar la integridad del territorio belga. La llamada "política de independencia” había sido reconocida por las principales potencias europeas y había contribuido a la disolución de lo que quedaba de Locarno, pues significaba que los Acuerdos de Londres del 19 de marzo de 1936 eran ya papel mojado. Además, el frente común que los británicos y franceses buscaban para establecer unas bases sólidas de negociación con Alemania ya no tenía sentido. Bélgica había permitido que Alemania actuase tal y como deseaba, es decir, evitando la negociación con un bloque. Ofreció al gobierno alemán una negociación bilateral que actuase como antesala a la negociación de un posterior pacto de seguridad. Un pacto de seguridad que nunca se concretó. Locarno se disolvió como un azucarillo en el café, y en 1938 las negociaciones ni siquiera se retomaron. Pues bien la política exterior belga tuvo un papel relevante en todo esto.

Así, Locarno vino a significar un doble fracaso. El 7 de marzo de 1936 la remilitarización de la Renania supuso una oportunidad perdida para calibrar a Hitler antes del rearme alemán ${ }^{147}$. Pero, además, el inconcluso proceso de negociación que se ha detallado en este texto acabó por significar el final de una época, la de un endeble sistema de seguridad colectiva. Lo que vino después - Anschluss, Checoslovaquia,...reflejó, en palabras del poeta británico Stephen Spender, el nacimiento de una nueva: el comienzo de una guerra ${ }^{148}$.

147. STEINER «The Triumph...» op. cit. p. 158.

148. Spender, Stephen, Un mundo dentro del mundo, Barcelona: Aleph Editores, 1993, pp. 311-312. 